УДК $630 * 8$

\title{
ИСПОЛЬЗОВАНИЕ ОТРАБОТАННОЙ ДРЕВЕСНОЙ ЗЕЛЕНИ ПИХТЫ В КАЧЕСТВЕ ДОБАВКИ ПРИ ПРОИЗВОДСТВЕ ДРЕВЕСНОВОЛОКНИСТЫХ ПЛИТ
}

(ㄱ С.О. Медведев", Л.И. Лазарева

\author{
Лесосибирский фрилиал Сибирского государственного технологического \\ университета, ул. Победы, 29, Лесосибирск, 662543 (Россия), \\ e-mail: medvedev_serega@mail.ru
}

Обоснована возможность использования отработанной древесной зелени пихты сибирской в качестве добавки при производстве древесноволокнистых плит, изучено влияние фракционного размера, вида и вклада древесной зелени пихты на основные физико-механические свойства плит. Представлены уравнения зависимости выхода последних от рассматриваемых факторов.

Ключевые слова: древесноволокнистая плита, древесная зелень, измельчение, прочность.

\section{Введение}

При пихтоварении и экстрагировании древесной зелени лесосибирского региона в качестве полезной продукции потребляется около $20 \%$ сырья. Остальное складируется в лесу, создавая угрозу возникновения пожаров и нападения насекомых-вредителей. На малолесных территориях ее успешно перерабатывают на хвойную муку [1]. В данном случае она не востребована. В связи с этим возникает необходимость использования отработанной древесной зелени в какое-либо достаточное емкое производство.

В условиях лесосибирского промышленного узла, учитывая имеющийся опыт по переработке кусковых отходов, достаточно обоснованным представляется использование этого сырья в производстве ДВП. При решении вопроса о возможности утилизации отработанной древесной зелени в качестве ингредиента ДВП поставлена серия опытов с добавлением в исходную массу разного количества этого сырья [2].

\section{Экспериментальная часть}

В экспериментах использовали сухую отработанную древесную зелень пихтоварения, источниками которой служили дифференцированные по возрасту деревья пихты, произрастающие в лесосибирском районе (среднеенисейской тайге). После сушки ее перемалывали на мельнице для измельчения древесной зелени и просеивали. В опытах применяли фракции размером $0,2-0,8$ мм. Предварительно в ходе поискового эксперимента было установлено, что использование более крупных фракций не целесообразно вследствие сложностей при формировании древесноволокнистых полуфабрикатов. Полученное сырье добавляли в стандартную, потребляемую для изготовления мокрым способом ДВП смесь на стадии включения прочих добавок в количестве 4-16\%. Источником волокнистого полуфабриката выступало сырье, применяемое при производстве ДВП на ОАО «Лесосибирский ЛДК №1». Смесь тщательно перемешивали и в дальнейшем перерабатывали в

Медведев Сергей Олегович - ассистент кафедры экономики и управления на предприятии, e-mail: medvedev_serega@mail.ru

Лазарева Любовь Ивановна - старший преподаватель кафедры технологии производства в лесном комплексе, тел.: (39145) 6-28-03, e-mail: lazarewa.lyuba @ yandex.ru соответствии с принятой технологией производства плитного материала [3, 4]. Качество полученных плит оценивали по значению их физико-механических показателей, определяемых стандартными методами, приведенными в ГОСТ 4598-86, в лабораторных и производственных условиях.

\footnotetext{
* Автор, с которым следует вести переписку.
} 


\section{Результаты и обсуждение}

Результаты анализа физико-механических показателей плит, проведенного при дублировании в трехкратной повторности, представлены в таблице 1.

Проведенные исследования [5] указывают на реальную возможность получения древесноволокнистых плит с добавкой отработанной древесной зелени пихты. Возможно включение в рабочую массу при производстве от 4 до 12\% данного вторичного сырья. При этом основные характеристики плит находятся в

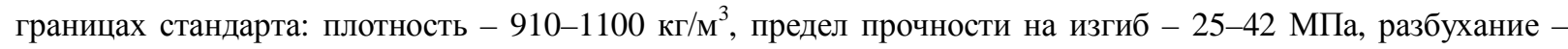
10-25\%, водопоглощение за 24 ч - 20-32,5\%. Наиболее чувствительным параметром в данном случае оказался последний параметр. В случае включения добавки в размере $12-15 \%$ существенно падают качественные показатели плит, незначительно выходя за границы нормативов. При добавлении более $15 \%$ сухой отработанной зелени в рабочую массу происходит расслаивание получаемых плит, что, по-видимому, объясняется ослаблением связей добавки с волокном. Аналогичные результаты получаются при укрупнении размера добавляемой отработанной зелени. Кроме этого, добавляемое сырье обладает меньшей плотностью, что вызывает его всплывание при формировании древесноволокнистого ковра и неравномерное распределение по телу плиты и ковра, ведущее к отмеченным выше недостаткам.

Полученные данные обрабатывали статистически с использованием стандартных методов и программного комплекса Statistica. Их обработка позволяет построить математические модели, описывающие исследуемые процессы.

Зависимость анализируемых физико-механических показателей полученного материала от исследуемых параметров, с учетом введения отработанной древесной зелени в состав основной древесноволокнистой композиции, представлена выражениями:

$$
\begin{aligned}
& \text { - плотности } \\
& P=23742,05-186,87 \mathrm{q}-642,22 \mathrm{f}+1,05 \mathrm{q}^{2}+3,22 \mathrm{f}^{2}+1,71 \mathrm{q} \cdot \mathrm{f}+14285,50 \mathrm{x}-4627,63 \mathrm{x}^{2}+0,21 \mathrm{q} \cdot \mathrm{x}-4,08 \mathrm{f} \cdot \mathrm{x} \\
& \text { - прочности на изгиб } \\
& \quad \mathrm{Pr}=-1580,13-16,85 \mathrm{q}+50,07 \mathrm{f}-0,03 \mathrm{q}^{2}+0,34 \mathrm{f}^{2}+0,08 \mathrm{q} \cdot \mathrm{f}-1087,40 \mathrm{x}-101,90 \mathrm{x}^{2}+0,98 \mathrm{q} \cdot \mathrm{x}+13,33 \mathrm{f} \cdot \mathrm{x} \\
& \text { - } \text { разбухания } \\
& \quad \mathrm{S}=-16327,40+10,11 \mathrm{q}+453,49 \mathrm{f}+0,56 \mathrm{q}^{2}-2,22 \mathrm{f}^{2}-0,18 \mathrm{q} \cdot \mathrm{f}-9761,07 \mathrm{x}+3371,80 \mathrm{x}^{2}-1,24 \mathrm{q} \cdot \mathrm{x}-3,23 \mathrm{f} \cdot \mathrm{x} \\
& \text { - водопоглощения } \\
& \mathrm{R}=-35749,20+127,00 \mathrm{q}+965,86 \mathrm{f}+0,08 \mathrm{q}^{2}-4,66 \mathrm{f}^{2}-1,24 \mathrm{q} \cdot \mathrm{f}-21459,40 \mathrm{x}+7120,20 \mathrm{x}^{2}-0,87 \mathrm{q} \cdot \mathrm{x}+1,18 \mathrm{f} \cdot \mathrm{x}
\end{aligned}
$$

\begin{tabular}{|c|c|c|c|c|c|c|}
\hline № & $\begin{array}{c}\text { Вклад } \\
\text { твердых } \\
\text { отходов, } \\
\%\end{array}$ & $\begin{array}{c}\text { Размер частиц, } \\
\text { мм }\end{array}$ & $\begin{array}{l}\text { Плотность } \\
(\rho), \kappa \Gamma / \mathbf{M}^{3}\end{array}$ & $\begin{array}{c}\text { Предел } \\
\text { прочности } \\
\text { на изгиб } \\
\text { (Pr), МПа }\end{array}$ & $\begin{array}{c}\text { Разбухание } \\
\text { (R), \% }\end{array}$ & Водопоглощение (S), \% \\
\hline 1 & 4 & 0,2 & $910 \pm 2$ & $41,6 \pm 0,4$ & $9,9 \pm 0,1$ & $20,0 \pm 0,2$ \\
\hline 2 & 8 & 0,2 & $920 \pm 2$ & $42,2 \pm 0,4$ & $9,8 \pm 0,1$ & $20,1 \pm 0,2$ \\
\hline 3 & 12 & 0,2 & $915 \pm 2$ & $39,8 \pm 0,3$ & $10,1 \pm 0,1$ & $21,2 \pm 0,2$ \\
\hline 4 & 16 & 0,2 & $990 \pm 3$ & $28,2 \pm 0,2$ & $16,2 \pm 0,2$ & $26,7 \pm 0,3$ \\
\hline 5 & 4 & 0,4 & $920 \pm 2$ & $37,2 \pm 0,3$ & $10,2 \pm 0,1$ & $20,6 \pm 0,2$ \\
\hline 6 & 8 & 0,4 & $940 \pm 2$ & $39,8 \pm 0,3$ & $10,0 \pm 0,1$ & $20,7 \pm 0,2$ \\
\hline 7 & 12 & 0,4 & $945 \pm 2$ & $34,5 \pm 0,3$ & $10,2 \pm 0,1$ & $21,9 \pm 0,2$ \\
\hline 8 & 16 & 0,4 & $995 \pm 3$ & $28 \pm 0,2$ & $17,3 \pm 0,2$ & $27,9 \pm 0,3$ \\
\hline 9 & 4 & 0,6 & $935 \pm 2$ & $36,2 \pm 0,3$ & $10,3 \pm 0,1$ & $20,9 \pm 0,2$ \\
\hline 10 & 8 & 0,6 & $945 \pm 2$ & $39 \pm 0,3$ & $10,4 \pm 0,1$ & $21,2 \pm 0,2$ \\
\hline 11 & 12 & 0,6 & $952 \pm 2$ & $37,5 \pm 0,3$ & $10,8 \pm 0,1$ & $22,8 \pm 0,2$ \\
\hline 12 & 16 & 0,6 & $1050 \pm 3$ & $27 \pm 0,2$ & $18,9 \pm 0,2$ & $29,3 \pm 0,3$ \\
\hline 13 & 4 & 0,8 & $962 \pm 2$ & $35,6 \pm 0,3$ & $10,8 \pm 0,1$ & $21,6 \pm 0,2$ \\
\hline 14 & 8 & 0,8 & $980 \pm 2$ & $37,9 \pm 0,3$ & $11 \pm 0,1$ & $22,3 \pm 0,2$ \\
\hline 15 & 12 & 0,8 & $990 \pm 3$ & $36,1 \pm 0,3$ & $11,5 \pm 0,1$ & $23,8 \pm 0,2$ \\
\hline 16 & 16 & 0,8 & $1100 \pm 4$ & $25 \pm 0,2$ & $21,5 \pm 0,2$ & $32,5 \pm 0,4$ \\
\hline
\end{tabular}

где q - вклад древесной зелени в древесноволокнистой композиции, \%; f - фракционный размер древесной зелени, мм; х - вид отработанной древесной зелени (1 - сырье после пихтоварения, 2 - этанольного экстрагирования).

Таблица 1. Результаты анализа древесноволокнистых плит с добавлением твердых остатков пихтоварения 
Графические зависимости полученных моделей прочности на изгиб и плотности, характеризующие влияние входных факторов на выходную величину, представлены на рисунке 1.

В прикладном плане важен вопрос о возможности использования в производственном процессе отработанной при пихтоварении и этанольном экстрагировании древесной зелени. При его решении проведена серия опытов с включением в рабочую массу композиции охвоенных побегов исследуемых образцов. Вклад добавляемого сырья составлял от 4 до 16\%, размер частиц - от пыли до 1,0 мм. Изготовленные плитные материалы анализировали на прочность. Экспериментальные данные по влиянию содержания добавленной отработанной при пихтоварении и этанольном экстрагировании древесной зелени с размером частиц 0,4 мм в интервале от 4 до 16\% представлены на рисунке 2.

Результаты исследований показали, что наличие в древесной зелени незначительного количества эфирного масла (отходы пихтоварения) практически не сказывается на прочности плиты [6, 7]. Характер обоих кривых одинаков, расхождение величины показателей прочности на изгиб при одинаковом вкладе сырья находится в пределах ошибки эксперимента. Тем не менее достаточно отчетливо отмечается тенденция превышения прочности изделий с древесной зеленью, подвергшейся этанольному экстрагированию. Наибольшей прочностью обладают плитные материалы с добавлением $8 \%$ исследуемого сырья.

О высоком качестве плит с добавлением древесной зелени свидетельствуют и результаты микроскопирования образцов, полученных с включением в рабочую композицию отработанной древесной зелени $(0,4$ мм, $8 \%)$. Достоинством данного плитного материала, проявляющегося в его более значительной плотности, является малое количество пустот, обусловливаемое включением частиц охвоенных побегов между частицами стандартного сырья.

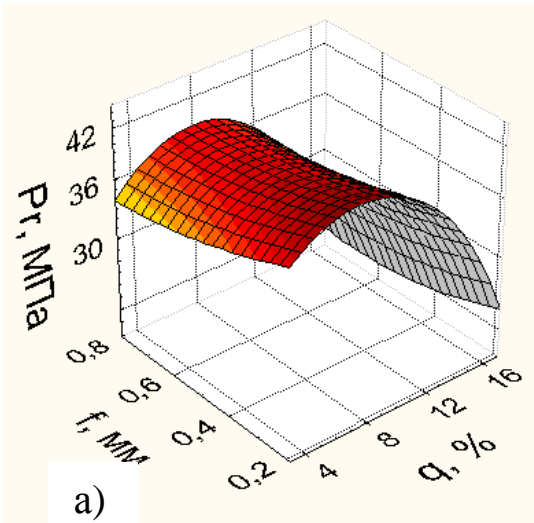

a)

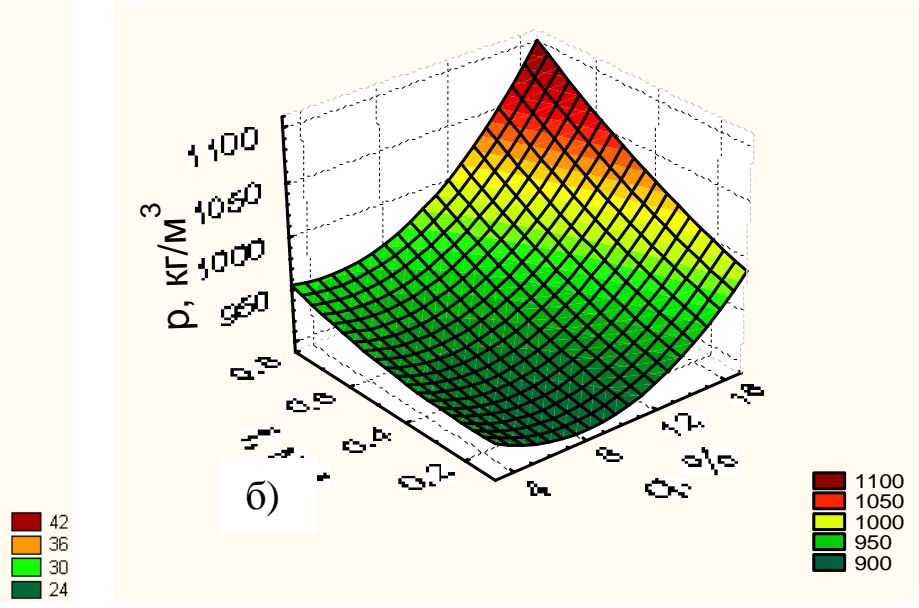

Рис. 1. Зависимость а) прочности на изгиб и б) плотности плит от вклада и размера частиц добавляемого сырья

Рис. 2. Влияние вклада отработанной пихтоварением и этанольным экстрагированием древесной зелени на прочность плит

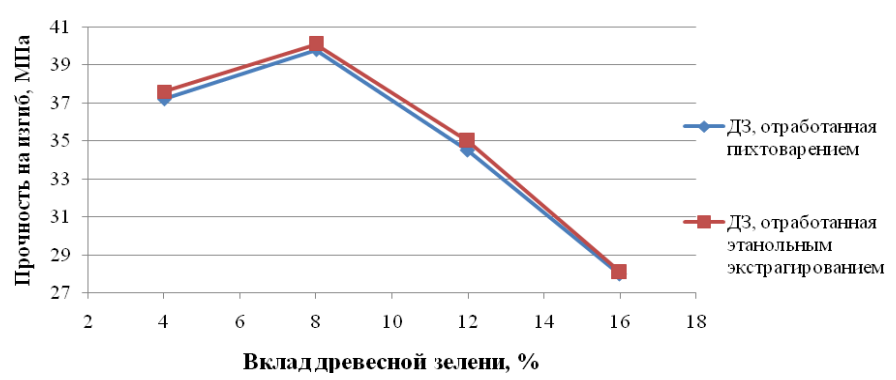

\section{Выводы}

Согласно данным исследования, для изготовления товарной продукции, соответствующей требованиям стандартов по основным оцениваемым параметрам (прочность на изгиб, плотность, водопоглощение и разбухание за 24 ч), допустимо включение в качестве добавки отработанной древесной зелени пихты сибирской после пихтоварения и этанольного экстрагирования. Ее максимальный вклад в плитный материал составляет 12\%, размер частиц - от пыли до 0,4-0,6 мм. При соблюдении этих ограничений полученные изделия обладают более высокой плотностью и прочностью на изгиб, хотя и меньшими водопоглощением 
и разбуханием. Их органолептические показатели не уступают таковым стандартных плит ДВП. В промышленных условиях границы вклада и размера частиц отработанной древесной зелени могут быть расширены вследствие более качественного процесса формирования древесноволокнистого ковра на действующих производствах, нежели чем в лабораторных условиях. Также установлено, что наличие в древесной зелени незначительного количества эфирного масла (отходы пихтоварения) практически не сказывается на прочности плиты.

\section{Список литературь}

1. Лобанов В.В., Степень Р.А. Влияние биоценотических факторов на содержание и состав пихтового масла // Хвойные бореальные зоны. 1995. №2. С. 148-155.

2. Медведев С.О. Использование измельченной древесной зелени пихты сибирской в качестве добавки при производстве ДВП // Экология, рациональное природопользование и охрана окружающей среды. Красноярск, 2011. С. $120-121$.

3. Бекетов В.Д. Повышение эффективности производства древесноволокнистых плит. М., 1988. 160 с.

4. Пучков Б.В. Использование древесных отходов для производства плит. М., 2005. 56 с.

5. Медведев С.О., Степень Р.А. Перспективы получения ДВП с измельченной древесной зеленью // Молодые ученые в решении актуальных проблем науки: сб. ст. Всерос. науч.-практ. конф. (с междунар. участием). Красноярск, 2011. Т. 2. С. 32-34.

6. Медведев С.О. Инновации в технологиях потребления древесной зелени // Научный потенциал молодежи - будущее России: сб. тез. докл. III Всерос. молод. науч. конф. Муром, 2011. С. 103-104.

7. Медведев С.О., Степень Р.А., Соболев С.В. Развитие современного лесопромышленного кластера в Красноярском крае // Известия вузов. Лесной журнал. 2011. №4. С. 131-136.

Поступило в редакичию 16 февраля 2012 2.

Medvedev S.O. , Lazareva L.I. INFLUENCE OF AGE AND PLACING IN A CRONE OF WOOD GREENS ON AN EXIT OF LIPIDS AND FIR OIL OF AN ÁBIES SIBÍRICA OF LESOSIBIRSK REGION

Siberian State Technological University (Lesosibirsky branch), ul. Pobedy, 29, Lesosibirsk,, 662543 (Russia), e-mail: medvedev_serega@mail.ru

In the article necessity of use the fulfilled wood greens of an Ábies sibírica as an additive is proved by manufacture of wood-fiber plates, influence of the fractional size, a kind and the contribution of wood greens of a fir on the basic physicomechanical properties of plates is studied. The equations of dependence of an exit of the last from considered factors are presented.

Keywords: Wood-fiber plate, wood greens, crushing, durability.

\section{References}

1. Lobanov V.V., Stepen' R.A. Khvoinye boreal'nye zony, 1995, no. 2, pp. 148-155. (in Russ.).

2. Medvedev S.O. Ekologiia, ratsional'noe prirodopol'zovanie i okhrana okruzhaiushchei sredy. [Ecology, environmental management and environmental protection.]. Krasnoyarsk, 2011, pp. 120-121. (in Russ.).

3. Beketov V.D. Povyshenie effektivnosti proizvodstva drevesnovoloknistykh plit. [Improving the efficiency of production of fibreboard]. Moscow, 1988, 160 p. (in Russ.).

4. Puchkov B.V. Ispol'zovanie drevesnykh otkhodov dlia proizvodstva plit. [The use of wood waste for the production of slabs]. Moscow, 2005, 56 p. (in Russ.).

5. Medvedev S.O., Stepen' R.A. Molodye uchenye v reshenii aktual'nykh problem nauki: sbornik statei vseros-siiskaia nauchno-prakticheskaia konferentsiia (s mezhdunarodnym uchastiem). [Young scientists in solving actual problems of science: a collection of articles Russian Scientific and Practical Conference (with international participation)]. Krasnoyarsk, 2011, vol. 2, pp. 32-34. (in Russ.).

6. Medvedev S.O. Nauchnyi potentsial molodezhi - budushchee Rossii: sbornik tezisov dokladov III vserossiiskoi molodezhnoi nauchnoi konferentsii. [The scientific potential of the youth - the future of Russia: Book of Abstracts of the III All-Russian Youth Conference]. Murom, 2011, pp. 103-104. (in Russ.).

7. Medvedev S.O., Stepen' R.A., Sobolev S.V. Izvestiia vuzov. Lesnoi zhurnal, 2011, no. 4, pp. 131-136. (in Russ.).

\footnotetext{
* Corresponding author.
} 